\title{
Analysis of direct human influences and its adverse impacts on the ecosystems of world heritage site (Sundarbans)
}

\author{
Awal, Mohd Abdul \\ Environmental Scientist, (Ministry of Environment \& Forest); Founder \& Chief Advisor, Health \& Pollution Research Farm, 23-09-37 \\ Avenue, Apt, No: 1, Long Island City, New York, USA
}

Email address:

abdul_awal2004@yahoo.com

\section{To cite this article:}

Awal, Mohd. Abdul. Analysis of Direct Human Influences and Its Adverse Impacts on the Ecosystems of World Heritage Site (Sundarbans). International Journal of Environmental Monitoring and Analysis. Vol. 2, No. 4, 2014, pp. 209-219.

doi: $10.11648 /$ j.ijema.20140204.14

\begin{abstract}
The Sundarbans is the largest single tract of mangrove forest in the world, occupying about $6,029 \mathrm{~km}^{2}$ in Bangladesh and the rest in India. At the advent of British rule in 1765, the Sundarbans forests were double their present size. Although, Sundarbans importantly supports local societies and economics, it is suffering a serious killer disease (top dying) which is affecting millions of the trees. The loss of $H$. fomes will have a major impact on the Sundarbans mangrove ecosystem and economic losses as well.The forest is seriously threatened by human destruction and by ecological pollution. The cause of this dieback is still unknown. The present work investigates one of the possible factors that might be causing this top-dying namely the concentrations of various chemical elements present in the soil or sediments, particularly, exchangeable Kand heavy metals concentrations, though other chemical parameters such as the $\mathrm{pH}$, moisture content of the soil or sediment and nutrient status were also assessed. A questionnaire survey was conducted among different groups of people inside and outside of Sundarbans to explore local perceptions as to the possible causes of top dying This confirmed the increase in top-dying prevalence due to human destructions and environmental pollutions.
\end{abstract}

Keywords: Human Destruction, Direct Extractions, Activities, Chemical Contamination, Causal Factors, Pollution, Heavy Metal Concentrations, Chemical Contamination, Sundarbans, Top-Dying

\section{Introduction}

Bangladesh is the one of the most densely populated countries, and it has about 147.37 million people in an area of $144,000 \mathrm{sq} \mathrm{Km}$. Bangladesh is facing many problems including all kinds of environmental pollutions (Awal, 2007), high population density and poverty; these problems being interlinked with each other (Awal, 2007, 2009, 2014). The total forest area of Bangladesh is about 2.47 million ha, which accounts for about $18 \%$ of the total land area of the country, and which constitutes $0.15 \%$ of the world's total tropical forests (Haque, 2000), although an estimate from 1993 gives tree cover at $5-7 \%$ of the country's area (FAO,1993). Sundarbans comprises $45 \%$ of the total productive forests in Bangladesh, and contributes about $50 \%$ of forest related revenue (Awal, 2007). The 1993 total wood supply in the country was 6.2 million $\mathrm{m}^{3}$ against a demand of 8.34 million $\mathrm{m}^{3}$, with a sustainable local supply for only 1.3 million $\mathrm{m}^{3}$. Sixty five percent of forest products are consumed as fuel wood (GOB, 1993).

These unique coastal tropical forests Sundarbans mangroves forest are among the most threatened habitats in the world (Awal, 2007, 2009, 2014). They may be disappearing more quickly than inland tropical rainforests (Awal, 2007), and having so far, with little public awareness (Awal, 2007).

\subsection{Importance of Sundarbans Ecosystem}

The Sundarbans provide critical habitat for a diverse marine and terrestrial flora and fauna (Awal, 2007), and 3.5 million people depend on Sundarbans forests and waterways for their survival (Anon, 1986; Chaffey et al, 1985). Approximately 2.5 million people live in small villages surrounding the Sundarbans, while number of people within $20 \mathrm{~km}$ of the Sundarban with a boundary (Islam, 1993). Sundarbans supports potential fishery, honey, wood for construction purposes, fuel wood, thatching materials, wax, deer's meats, and natural forest resources 
and constitutes an important commercial and artisanal fishery industry that produces fresh fish, iced fish, sun dried fish, and smoked fish, salted fish, fish meal and sharks oil (Figure 1.0). Sundarbans provides a considerable harvest of whitefish, shrimps, prawns, mud crabs, snails / oysters and billions of shrimps, prawns, and post larvae for shrimp aquaculture farms (Awal, 207, 2009, 2014). These industries support about 155,000 fishermen throughout the year, and economic valuation of the fisheries function of mangroves was estimated to range from US\$ 66 to almost 3,000 per ha (Hambrey, 1999). Sundarbans also supports the livelihood and earnings for about two million people of the adjoining areas at least part of the year i.e. during the winter season for fishing, collection of Golpata leaf (Nypafruticans) and Goran (Ceriopsdecandra) fuel wood (Hussain and Karim, 1994). The local Apisdorsatahas a high commercial importance (Awal, 2007, 2009, 2014). Traditional honey hunting is an interesting item for the tourists operated during April to July each year (Awal, 207, $2009,2014)$. About $30,000 \mathrm{~kg}$ of honey and $80,000 \mathrm{~kg}$ of raw wax are harvested annually (Islam, 1993). These products are widely used in the pharmaceutical industries (Awal, 2007, 2009, 2014). According to Guha (1989), historically there has been the transformation of resource utilization patterns by both the relevant government departments and traditional users. Paramount among these changes were shifting from communal to individualized forms of use, as encouraged by the permit system and by leasing rights and employment practices introduced by the Forest Department (Awal, 2007, 2009, 2014).

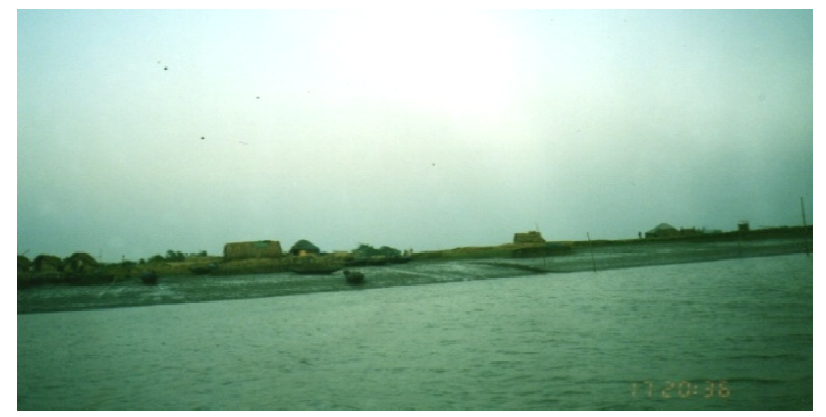

Figure 1.0. Photograph of part of the Sundarbans coastal area, near compartment number 26, where the trees have been cut down to be replaced by a fishing village.

\subsection{Threats and Policies}

Enrichment and illicit removal of timber and firewood and other natural resources from the forests are the most and major forest conservation problems in Sundarbans (Awal, 2007, 2009, 2014). The annual average destruction of forest land in the country was 8000 ha in 1980 and subsequently it increased to 38000 ha in 1981-90 according to FAO (1993). But probably the rate of destruction of forest is more severe than the official statistics as it is very difficult to estimate the real picture (Awal, 2007, 2009, 2014). Deforestation affects one eighth of the country's land areas (Awal, 207, 2009, 2014). The Bangladesh government has now officially banned the felling, realizing that the forest had degraded due to excessive felling (Awal, 2007).

Possibly, many factors contributed to loss of Sundarbans, including the charcoal and timber industries, but also urban growth pressures and mounting population pressure and environmental-pollution (Awal, 2007). The significant and recent causes of Sundarbans mangrove loss in the past decade have included the customer demands for luxury shrimp (Awal, 2007, 2009, 2014), or "prawns", and the destructive production methods of export-oriented industrial shrimp farms and factories. The failure of governments to adequately regulate the shrimp industry, and the headlong rush of multilateral lending agencies to fund aquaculture development without meeting their own stated ecological and social criteria have all played a part.Approximately 100,000 to 200,000 people work inside the Sundarbans for at least 6 months (Awal, 2007, 2009, 2014), while the number of people entering the forest in a year could be as high as 3,000,000 (Hussain and Karim, 1994). Of these, about 25,000 people work in fish drying and $60,000-90,000$ people in shrimp post-larvae collection inside the Sundarbans (FAO, 1994). About one million people are engaged in shrimp larval collection in the rivers and creeks around the outside of the Sundarbans (Chantarasri, 1994).

The state policy towards the Sundarbans began in the 1770s. In 1785, TilmanHenckell, the judge-magistrate in Jessore, gave out 150 leases and established three market towns in the area (Awal, 2007). The Sundarbans always belonged to the state and did not come under the purview of the Permanent Settlement Act of 1790; Zamindars or landlords were not to collect revenues or taxes from the Sundarbans (Awal, 2007). In 1862, Dr. Brandis, the Conservator of Forests in Burma, put up a convincing argument in favor of preserving the Sundarbans (Banerjee, 1964). Additional reclamation grants were stopped, but forest was leased to the port Canning Company. This was a company newly formed to build a replacement to the port of Calcutta, which was considered to be dying because of the silting up of the Hooghly River (Awal, 207, 2009, 2014). However, the lease was cancelled in 1868 because of the Company's oppressive behavior toward the traditional users of the forest (Banerjee, 1964). On December 7, 1878, Dr. Brandis' intercession became effective, and portions of the Sundarbans were declared "reserved" and "protected" (Mukherjee, 1975).

\subsection{Indirect Human Destruction in Sundarbans}

The Sundarbans, like other tidal natural forests, is tolerant of natural disturbances such as the cyclones and tidal waves of the Bay of Bangle, but it is highly vulnerable to human disturbances (Seidensticker and Hai, 1983). Most of the abuses found in professional forestry management elsewhere have been observed here as well, such as excessive cutting of stocks in the auctioned area (Awal, 2007, 2009, 2014), and connivance between purchasers and 
forestry staff to cut wider areas than sanctioned (Bari, 1993). The major usable forest species include a wide variety of mangroves, and government auction of trees such as the Excoecariaagallocha, Heritierafomes, and Nipafruticans have brought substantial revenues each year (Bari, 1993). Excoecariaagallocha is the principal supply of raw-material for the Khulna Newsprint Mills, a 48,000ton facility built in 1959, and a significant (GRPB, 1985) export earner. Much, if not most, of this industry was situated to the east of Sundarbans, but there appeared to be considerable interest in increasing crustacean culture in the reserved forest (GRPB, 1985), an interest doubtless spurred by the Government target for exporting shrimp included in the 1985-90 five-year-Plan (GRPB, 1985).

Another factor is a long-term ecological change which is taking place in the Sundarbans due to the eastward migration of the Ganges, abandonment of some tributaries, diversion of water and withdrawals for irrigation and also all kinds of human destructions (Awal, 207, 2009, 2014). Up to $40 \%$ of the dry season flow of the Ganges has been diverted upstream, following the completion of the Farraka Barrage in India in 1974 (Awal, 207, 2009, 2014). Decreased freshwater flushing of the Sundarbans results in increased saline intrusion, particularly in the dry season (Awal, 2007, 2009, 2014). Concern has been expressed about recent indications of apparent deterioration in the flora, including localised dieback of Sundri (Awal, 2007, 2009, 2014), commercially the most valuable tree species, which might be associated with the decrease in freshwater flow (Awal, 2007, 2009, 2014), either as a direct effect of increasing salinity or other associated edaphic changes (Awal, 2007, 2009, 2014). A gradual replacement of Heritierafomes with Excoecariaagallocha (Awal, 2007, 2009, 2014), therefore, is a likely long term effect (Christensen, 1984), and certainly deterioration in the vegetation is already well-documented (International Engineering Company, 1980). Besides recent changes in vegetation, geomorphic changes in the Sundarbans environment are also rapid (Personal observation; Faizuddin, 2003). Also, there were 157 major oil spills in tropical seas between 1974 and 1990 (Burns et al., 1993). Deep mud coastal habitats may take 20 years or more to recover from the toxic effects of such oil spills (Phillips et al., 1994).

\subsection{Direct Human Destructions}

Three major match factories, two in Khulna and one in Dhaka, depend on the Sundarbans for their raw materials; the total daily requirement of wood for these three factories is 320 tons (Anonymous, 1986). The Khulna hardboard mill uses entirely Sundri (Heritierafomes) of about $5-15 \mathrm{~cm}$ in diameter and 1-3 $\mathrm{m}$ in length, and the mill's annual requirement for raw material varies from 19,000 to 28,000 cubic meters stacked volume (Anon, 1986). Several forest based industries in Khulna also depend entirely on the Sundarbans (Anon, 1986). The quantities of minor forest produce from the Sundarbans during 1982-83 were Golpatta (Nipafruiticans), 62,000 tons, honey 232 tons, beeswax 58 tons, and shells 2,200 tons (Chaffey, et al., 1985); and Islam (1993) reported $80,000 \mathrm{~kg}$ of beewax being harvested annually.

\subsection{Barrage Construction and Water Flow Changes}

In the early $1970 \mathrm{~s}$, the Government of India constructed the Farakka barrage $(2,745 \mathrm{~m})$ and put it into full operation in 1975 across the Ganges some $19 \mathrm{~km}$ from the Bangladesh border (Awal, 2007). Due to this barrage, some new islands have formed, and siltation has begun to accumulate along the shore of the islands as well as sand being blown or washed away (Seidensticker and Hai, 1983) Apart from Baleswar River the waterways carry little freshwater as they are cut off from the Ganges, the outflow of which has shifted from the Hooghly-Bhagirathi channels in India progressively eastwards since the $17^{\text {th }}$ century (Awal, 2007). They are kept open largely by the diurnal tidal flow (Seidensticker and Hai, 1983).

\subsection{Shrimp Farming}

Sundri and other important plant species in surrounding areas of Sundarbans have been adversely affected by the establishment of shrimp farms for shrimp cultivation (Awal, 2007, 2009, 2014). Massive extraction of wild post larvae shrimp affects the stocks of natural resources (Awal, 2007, 2009, 2014). Satellite images show the expansion of the shrimp farming industry within the wetlands of the Gulf including Sundarbans recently, which changes the mangroves, lagoons and estuaries, and results in (Awal, $2007,2009,2014$ ) a net loss of habitat for native and migratory birds, fishes, molluscs, crustaceans, mammals, biological diversity and aquatic resources severely (Awal, 2007, 2009, 2014). Along with habitat changes, biodiversity is strongly impacted by the practice of catching post larval shrimp along with any other accompanying fauna, and separating out the shrimp while exterminating the other fauna by allowing the rest of the catch to die on the ground (Awal, 2007, 2009, 2014), or applying chemicals that do not harm shrimp but kill other species(Awal, 2007, 2009, 2014; own observation staying in Sundarbans as head of east wildlife sanctuary from 1993-1886). Post larvae shrimp usually make up approximately $10 \%$ of the catch; leaving $90 \%$ to be exterminated (reviewed by FAO, 1982). Shrimp culture might be associated with deteriorating mangrove conditions in the western part of the Sundarbans (Chaffey et al., 1985).

According to Phillips (1994), tropical shrimp farming has a long history, dating back at least 400 years (e.g. the 'tambaks' of Indonesia, 'bheris' and 'gera' of Bangal and tidal ponds in Ecuador) the expansion of the industry over the last 15 years has been extremely rapid and its environmental impact is now the subject of grave concern (Phillips, 1994). In the Khulna District of Bangladesh, artificial shrimp farms (locally called gher) are flooded with brackish water in the dry season months for shrimp culture (Nuruzzaman, 1990). For economic reasons 
associated with the high price of shrimp, such partial or complete switches from rice farming to aquaculture are putting further pressure on the remaining mangroves (Awal, 2007, 2009, 2014). For examples, Thailand has lost a total of 203,000 ha, $52 \%$ of the mangrove resource, due to shrimp-culture since 1961 (Anon, 1975; Briggs, 1991). Similar events are taking place in many other areas of the world; in Indonesia, most of the 300,000 ha of land being used to culture shrimp was ex-mangrove forest and the government of that country is planning to raise this figure to more than 1 million ha. By 1985, Java had lost $70 \%$ of its mangroves, Sulawesi $49 \%$ and Sumatra $36 \%$ (Anonymous, 1975). A similar scenario exists in the Philippines where mangrove areas have shrunk from 448,000 ha in 1968 to 110,000 ha in 1991 and such destruction has had a devastating effect on coastal fisheries and has led to the marginalization of subsistence fisherman and the erosion of shorelines (Singh, 1988).

It is estimated that 100 organisms (Awal, 2007, 2009, 2014) are destroyed for every shrimp-fry collected to supply extensive shrimp ponds ('gher') in Bangladesh (Awal, 2007, 2009, 2014); as many as $80 \%$ of the people in some coastal areas of the country are engaged in aquaculture seed collection (Awal, 2007, 2009, 2014). There is growing evidence that the environmental impacts of shrimp farming including all kinds of direct human destructions play a significant role in disease outbreaks, all sorts of environmental \& ecological pollutions and subsequent crop loss, as a result of the overloading of the carrying capacity of the environment (Awal, 2007, 2009, 2014, Phillips et al., 1994). The result of this is an accumulation of wastes in the surrounding ecosystems which may lead to severe and sometimes irreversible problems (Awal, 2007, 2009, 2014). In the Khulna District of Bangladesh, poldered rice fields ('gher') are flooded with brackish water in the dry season months for shrimp culture, then a rice crop is grown in the wet seasons when the field can be flushed with freshwater (e.g. Nuruzzaman,1990). In Asia large tracts of back mangrove were cleared initially for agriculture, especially rice farming (reviewed by FAO, 1981, 1982).

\subsection{Effluent Discharge}

Effluent discharge from intensive shrimp farming has been put at 1.29 billion $\mathrm{cm}^{3}$ of effluent per year in Thailand (FAO Report, 1997), although it has not been assessed in Bangladesh (Awal, 2007, 2009, 2014). However, effluent discharge is a problem of Sundarbans (Personal communication Mongla Port Authority, Khulna, 1996).

A large number of industries are discharging untreated effluents directly into the river at Khulna which is carried down to the Sundarbans forests (Awal, 2007, 2009, 2014). The polluting industries are Khulna Newsprint Mill (KNM), Hardboard Mills, and some match factories, fish processing units, Golpata power station, some Jute mills and Khulna shipyard (Awal, 2007, 2009, 2014). KNM alone continuously discharge nearly $4500 \mathrm{~m}^{3} /$ ha of waste water containing high levels of suspended solids (300-500mg/l) and sulphur compounds (UN-ESCAP, 1987). Moreover, resuspension of dredging material for port development is a potential threat to the Sundarbans due to long lasting toxicological effects from heavy metal pollution (Awal, 2007, 2009, 2014).

\subsection{Salt Production in Sundarbans}

In many regions of Asia with a seasonally dry climate, large areas of mangrove were cleared in early times for solar salt production (Awal, 2007, 2009, 2014). Today there are still areas diverted entirely too salt pans (Awal, 2007, 2009, 2014). Elsewhere salt production is rotated with shrimp farming in the wet season, as in the Sundarbans (Nuruzzaman, 1990). In addition to the physical loss of mangroves through coastal industrialization, there are also concerns over environmental effects from pollution. Deep mud coastal habitats may take 20 years or more to recover from the toxic effects of such oil spills, although aquaculture operations impact on the environment has increased recently (Phillips, 1994).

This section will explore whether there is any significant variation in the values determined for each of the chemical components of the soils in relation to which plot and which compartment they were sampled from. Analyses have been carried out using a two way analysis of variance, where the compartment was one factor and the plot (selected according to perceived increasing top-dying intensity) was the second factor. It should be noted, however, that particularly the second factor was not controlled, since it is not possible to be certain that the relative intensity of topdying of, for example, plot 2 in compartment 26 was equivalent to the relative top-dying intensity in plot 2 for compartment 31 . The interpretation of all results from the present analyses must therefore bear these points in mind.

\section{Methodology}

Nine (9) plots were selected for sampling, choosing areas to reflect different intensities of top-dying. Sixty-three sediment samples (63) were tested for the various parameters, including $\mathrm{x}$ elemental concentrations being determined by ICP-MS. The relationships between topdying and chemical or growth parameters were tested using correlation coefficients, the variations between plots were tested using analyses of variance and differences in seedling and sapling numbers using chi-square statistics. Results of seedling and sapling regeneration showed a marked reduction in numbers in areas with greater concentrations of several chemical parameters. However, adult tree growth was generally not correlated with the chemical parameters. Also, most of the individual elements and parameters studied had no significant correlation with the average intensity of top-dying of Heritierafomes. However, exchangeable $\mathrm{K}$, sediment moisture content and sediment $\mathrm{pH}$ were significantly related and $\mathrm{Sn}, \mathrm{Pb}, \mathrm{Zn}$ and $\mathrm{Ni}$ were also close to significance. 


\subsection{Field Sampling Methods}

Fieldwork was performed between October 2003 and March 2004. Sampling was from the area of the Sundarbans near Chandpai, which is the area most accessible to people and also potentially the one that is most polluted(Figure 2). Three areas from this area were selected (numbers 26, 28 and 31) because they represented a range of severity of top-dying disease as well as of human activities, as outlined in Awalet al. (2009). Within each of the three compartments, sampling of trees, mangrove sediment and water took place within three $20 \mathrm{~m} \times 20 \mathrm{~m}$ plots, chosen to reflect a range of top-dying intensities (high, medium and low for that area). The sampling was conducted in a randomized block design, in that a plot was sited within a particular top-dying intensity block. Therefore a total of nine plots were sampled. It should be noted that the material making up the mangrove sediments will include marine, coastal and freshwater deltaic sediments as well as biological material such as tree litter-fall. The relative importance of these sources will depend to a great extent on the patterns of river discharge (Dyer, 1986) and the extent of tidal inundation, and will also therefore vary spatially throughout the Sundarbans.

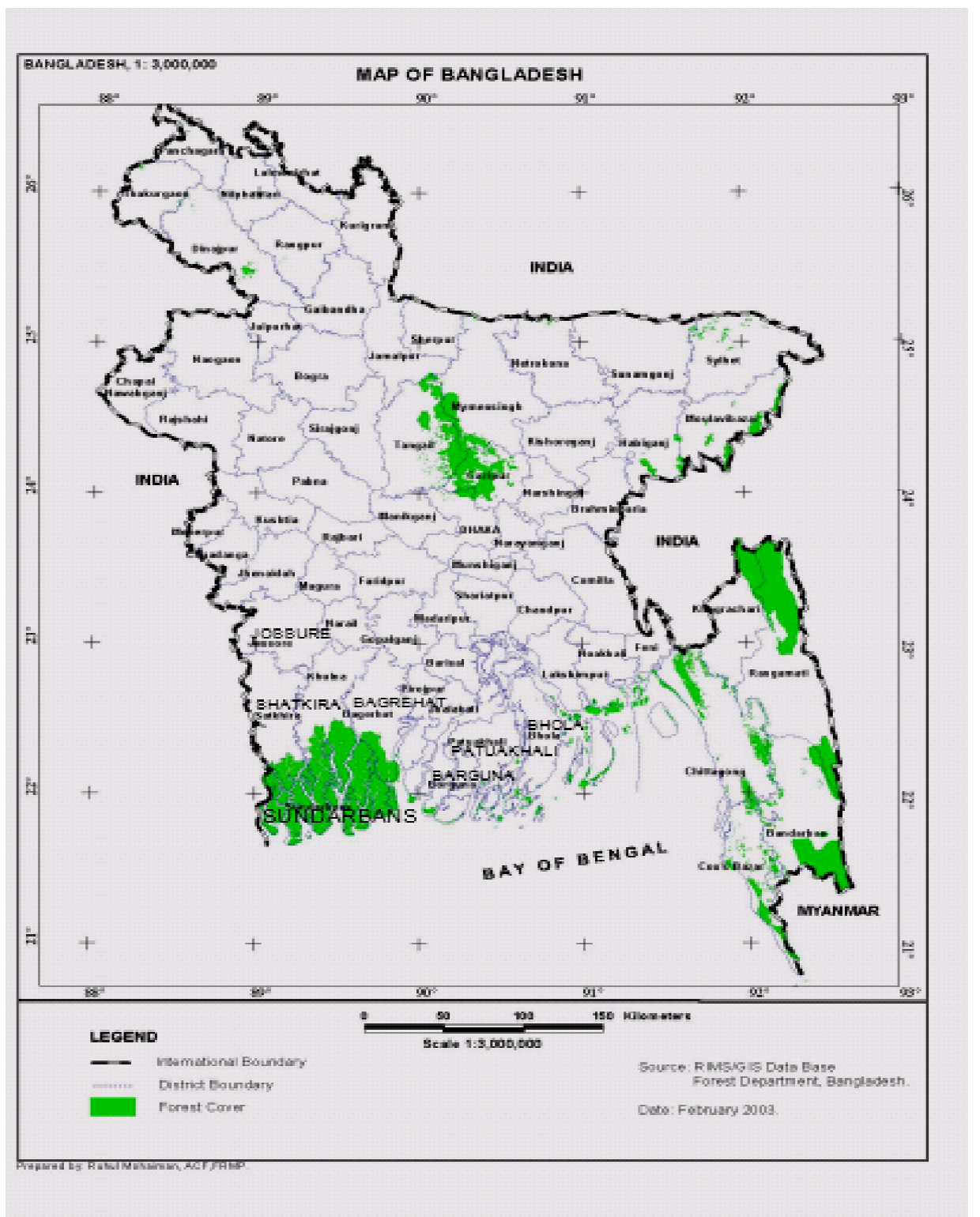

Figure 2.0. Map showing the administrative districts of Bangladesh, including the location of the Sundarbans (the shaded area in the south-west of the country)

From each of the nine plots, one water volume of sample was collected in a plastic bottle from a nearby river, creek or channel. Also, seven sediment samples were collected per plot; one from the centre of the plot, four (one each) from all the corners, and two from the middle sides of the plot. Therefore a total of 63 sediment samples was taken. These mangrove sediment samples were collected from 0 $30 \mathrm{~cm}$ depth by using a stainless steel spatula and steel cylinder $(d=5.25 \mathrm{~cm})$, and all samples were kept in sealed plastic bags until sample preparation took place. Samples 
were preserved in portable coolers until arrival at the laboratory at Dhaka University for initial chemical analysis and air drying. This field sampling method followed the W.H.O, U.K, and E.P.A systems of standard laboratory and field sampling principles, rules and regulations. The dried samples were later transported to Bradford, U.K., for chemical analysis by ICP-MS.Within each of the nine $20 \mathrm{~m}$ x $20 \mathrm{~m}$ plots, each adult tree of all species was assessed for three parameters. The diameter at $1 \mathrm{~m}$ height was recorded (in $\mathrm{cm}$ ) by using a measuring tape or slide callipers, depending on girth. The tree height to the top of the crown was determined mainly by ocular estimation, but some heights were checked by using clinometers at a set distance of $20 \mathrm{~m}$ to test the accuracy of such ocular estimations. Thirdly, the status of the tree in respect of the amount of top-dying was assessed by using a four point qualitative scale of intensity, namely; not affected, mildly affected, moderately affected or highly affected by top-dying(Figure 2). This was later expressed as a semi-quantitative or rank scale and used as an index of top-dying intensity in that plot. After assessing the adult trees, the total number of seedlings (individuals of the tree species $<1 \mathrm{~m}$ tall), and saplings (young trees $>1 \mathrm{~m}$ tall with a diameter of trunk of $<10 \mathrm{~cm}$ ), of all species were counted within the plots. Care was taken to ensure that trees, saplings and seedlings were not counted more than once or missed in the recording process by marking them, using different colours for adult and regenerating trees.

\subsection{Laboratory Analyses}

Initial chemical and physical properties of the mangrove sediment samples and the water were determined in Dhaka University. These were the electro-conductivity for the determination of sediment and water caution exchange capacity; the $\mathrm{pH}$ of both sediment and water; the percentage moisture content of the sediments; soil particle analysis determined by a Plunger Hydrometer; the concentrations of $\mathrm{S}$ (name of method?), soluble $\mathrm{N}$ (digestion method), and total $\mathrm{N}$ (Kjeldahl method. All remaining elemental concentrations were determined using Inductively Coupled Plasma - Mass Spectrometry (ICP-MS) at Bradford University.

\subsection{Electro-Conductivity}

Fifty $\mathrm{ml}$ of distilled water was added to $20 \mathrm{~g}$ of the sediment, and the mixture shaken mechanically and then stirred 5-7 times to ensure thorough mixing. The sediment suspension was left overnight for it to reach its stable suspension position phase. Finally water EC was recorded by using an EC meter.

\section{4. $\mathrm{pH}$}

The $\mathrm{pH}$ of the sediment samples was measured by adding $50 \mathrm{ml}$ of distilled water to [how much?] the sediment, then shaken and stirred 5-7 times to ensure thorough mixing. The mixture was left overnight for it to reach its stable suspension position phase before recording the $\mathrm{pH}$ using a $\mathrm{pH}$ meter. For the $\mathrm{pH}$ of the water samples, $50 \mathrm{ml}$ each of water sample and distilled water were taken, stirring was done in the same way as for the sediment $\mathrm{pH}$ measurement, and the sample solution left overnight before filtering using a Whatman No. 42 filter paper and then recording the $\mathrm{pH}$ as above.

\subsection{Particle Size Analysis}

Each sediment sample was air dried, ground to a powder, sieved, then reacted with hydrogen peroxide solution $\left(\mathrm{H}_{2} \mathrm{O}_{2}\right)$, according to the procedure described in Black et al. (1965). In the hydrometer, the blank reading was taken after 40 seconds, and the second reading after two hours, maintaining the temperature at $29^{\circ} \mathrm{C}$; and these values were used to calculate the particle size (Black et al., 1965).

\subsection{Percentage Moisture Content of the Sediment}

Approximately $50 \mathrm{~g}$ of sediment was passed through a 2 $\mathrm{ml}$ sieve. The sieved material was then weighed and heated to $105^{\circ} \mathrm{C}$ for 24 hours to dry it completely. The dry sediment was then reweighed and the difference in weights gave the weight of moisture. This amount of moisture was expressed as a percentage of the original wet sediment weight.

\subsection{Elemental Concentrations by ICP-MS}

Initial sample preparation was performed at Dhaka University. Adhering materials were removed with forceps, and all sample materials were dried at ambient temperature and were disaggregated to pass a laboratory test sieve using a brush. Soil samples were ground by an acid proof porcelain mortar pestle using a porcelain hammer. After making the soil into powder, samples were kept in plastic bags until later analysis.Subsequent analyses of the dried sediment samples were performed at Bradford University. In all steps of soil sample preparation and analysis, care was taken to avoid contamination. All items of equipment were first washed by hot tap water, soapy water, cold water, then by demonized water or distilled water and finally with acid leached in demonized water. For drying, all items were kept for 12 hours in an oven, and then they were washed again by the same procedure before storing, to be washed again immediately prior to starting a new analysis. Instruments were cleaned with appropriate blanks before beginning every experiment.

The 63 samples, together with two reference materials (namely peach leaf, 1547NIST, and estuarine sediment, 1646 NBS) and blanks as controls were prepared by adding $4 \mathrm{ml}$ of concentrated $1 \mathrm{M} \mathrm{HNO}_{3}$ solution to $0.2 \mathrm{~g}$ of the sample and pre-digested until the reaction of volatile or easily oxidized materials had subsided. Fresh blank samples were made for each separate set of acid digestions. Soil samples were digested by a Microwave Digestion System (MDS). All samples and solutions of material were kept in a cool room (at approximately $5^{\circ} \mathrm{C}$ ) until they were 
used for analysis. The samples were then sealed in Advanced Composite Vessels with a rupture membrane and pressure control cover in each, and heated in a microwave oven. The samples were heated slowly up to $103^{\circ} \mathrm{C}$, maintaining 175 psi pressure for 12 minutes. The resultant digest was cooled and collected by washing seven times with double-distilled water, filtered, then transferred to a volumetric flask and diluted to make $250 \mathrm{ml}$ volume.The samples were then analysed for 32 elements, this paper focusing on the 25 listed in Table 2 (list here if not giving the table in detail: $\mathrm{Al}, \mathrm{As}, \mathrm{B}, \mathrm{Ba}, \mathrm{Bi}, \mathrm{Ca}, \mathrm{Cd}, \mathrm{Co}, \mathrm{Cr}, \mathrm{Cu}, \mathrm{Fe}$, $\mathrm{Hg}$, In, K, Mg, Mo, Mn, Na, Ni, P, Pb, Rb, Sb, Sc, Se, Si, $\mathrm{Sn}, \mathrm{Sr}, \mathrm{Ti}, \mathrm{V}, \mathrm{Y}, \mathrm{Zn}$, though we could leave out some of the less relevant elements such as In, Rb, Sc and Y) using ICPMS. Calibration standards were required for checking the detector response, and these were prepared with known quantities of the elements at five concentrations $(1,10,100$, 200 and $1000 \mathrm{ppb}$ ) to cover the range of concentrations likely to be found for each element. The calibration standards are typically prepared using $2 \% \mathrm{HNO}_{3}$, but early trials suggested that there might be retention and crosscontamination of $\mathrm{Hg}$ within the equipment using this acid, and therefore $200 \mathrm{ppb}$ gold-wash solution was used instead which improved instrumental response (details in Awal, 2007).

\subsection{Statistical Analysis}

Data on the severity of top-dying for each tree in a plot, which had been recorded as 'not affected', 'mildly affected', 'moderately affected', and 'highly affected', were converted into a four-point scale (0-3), so that they could be summed and an average (median) could be determined for each plot, thus producing an average index score per plot based on ranked data. Comparisons of the strength of relationship between two variables were assessed by correlation: the Pearson's product-moment correlation coefficient where both variables were fully quantitative, or the Spearman's rank correlation coefficient where the top- dying index was one of the variables. In the case of the Spearman's coefficient, the probability of the outcome was determined by using the approximation to a t-statistic appropriate to these tests (Sokal and Rohlf, 1981). The Spearman's correlation was used here because the topdying data are based on an index, and probably not meeting all the assumptions of truly parametric data, although since the elemental concentrations are fully quantitative data, using this statistic will result in some information loss.Data on frequencies of seedlings or saplings in each of the plots and compartments were tested by $\chi^{2}$ contingency table analyses to determine whether the amount of top-dying was associated with location. A similar consideration of the different compartments as comprising one factor, and the plot type as a second, was used to test the pattern of elemental concentrations and other variables by a twofactor analysis of variance test with replication. This allows an assessment of the significance, not only of the two factors separately but also of the interaction between the two factors (Zar, 1984). It should be noted that the plot type was not a strictly controlled factor, since the three categories of top-dying intensity were relative to each other within any one compartment and might not have been exactly equivalent between the three categories in different compartments; interpretation of the results from these test therefore needs to bear this in mind.MINITAB version 14 Statistical Software has been used for all data analysis.

\section{Results}

These results show that the chemical composition of the soil appeared to be an important factor related to tree regeneration, though not to adult tree size, and in some cases to be related to the top-dying of Heritierafomes in Sundarbans. It is suggested that the latter effect is due to a weakening of the vigour of the trees, allowing other factors such as pathogenic agents to attack the plants.

Table 1.0. Mean $( \pm 1$ S.E.) and extreme heavy-metal elemental concentrations (ppb) in Sundarbans, together with comparisons with values from other published sources. An asterisk denotes a value below the limits of detection. Comparable data could not be found for all elements.

\begin{tabular}{|c|c|c|c|c|c|}
\hline \multicolumn{5}{|c|}{ Values from this study } & \multirow{2}{*}{$\begin{array}{l}\text { Values reported elsewhere } \\
\text { (Data refer to sediments unless otherwise stated; number within brackets } \\
\text { indicates source in footnote) }\end{array}$} \\
\hline Element & Minimum & Mean & S.E. & Maximum & \\
\hline $\mathrm{Al}$ & 0.89 & 16332.44 & 854.17 & 37570.00 & $420-585\left(\right.$ soil $\left.^{1}{ }^{1}\right) ; 8089000-46100000\left({ }^{1}\right) ; 500\left(\right.$ spring and well water, $\left.{ }^{2}\right)$ \\
\hline As & * & 4.56 & 0.24 & 10.06 & $3150-6830\left(^{7}\right)$ \\
\hline B & 0.55 & 19.20 & 2.14 & 103.80 & 2600 (spring and well water, ${ }^{2}$ ) \\
\hline $\mathrm{Ba}$ & 0.59 & 52.41 & 2.37 & 141.80 & $300\left(\right.$ spring and well water, $\left.{ }^{2}\right) ; 141$ (coastal soils, $\left.{ }^{5}\right)$ \\
\hline $\mathrm{Bi}$ & $*$ & 0.40 & 0.02 & 0.74 & \\
\hline $\mathrm{Cd}$ & 0.15 & 0.55 & 0.03 & 1.62 & $\begin{array}{l}0.52-0.92\left(\text { soil }^{1}\right) ; 300-13520\left({ }^{1}\right) ; 43-147\left({ }^{4}\right) ; 0.8\left(\text { coastal soils, }{ }^{5}\right) ; 11-65 \\
\left({ }^{7}\right)\end{array}$ \\
\hline Co & 5.93 & 31.31 & 5.65 & 143.60 & $\begin{array}{l}0-7.9\left(\text { ocean water, }^{3}\right) ; 3800-26000\left({ }^{1}\right) ; 10.6\left(\text { coastal soils, }{ }^{5}\right) ; 5540-15500 \\
\left({ }^{7}\right)\end{array}$ \\
\hline $\mathrm{Cr}$ & 3.11 & 15.72 & 3.39 & 114.90 & $\begin{array}{l}\left.\left.7 \text { (spring and well water, }^{2}\right) ; 1480-8560\left(^{4}\right) ; 41.2 \text { (coastal soils, }{ }^{5}\right) ; 12.8 \\
\left(\text { water, }^{6}\right) ; 33200\left({ }^{6}\right) ; 19500-46100\left(\left(^{7}\right)\right.\end{array}$ \\
\hline $\mathrm{Cu}$ & 1.85 & 10.52 & 1.71 & 43.76 & $\begin{array}{l}12.2-16.6\left(\text { soil }^{1}{ }^{)}\right) ; 12940-85600\left({ }^{1}\right) ; 22\left(\text { spring and well water, }{ }^{2}\right) ; 22-37.2 \\
\left.\left(\text { ocean water, }{ }^{3}\right) ; 2270-14730\left(\left(^{4}\right) ; 23.1 \text { (coastal soils, }{ }^{5}\right) ; 3.8 \text { (water, }{ }^{6}\right) ; 18200 \\
\left({ }^{6}\right) ; 6950-31600\left(^{7}\right)\end{array}$ \\
\hline $\mathrm{Fe}$ & 25.82 & 173891.10 & 9883.85 & 248200.00 & $\begin{array}{l}634-820\left(\text { soil },^{1}\right) ; 8080000-52000000\left({ }^{1}\right) ; 63\left(\text { spring and well water, }{ }^{2}\right) ; 6.2- \\
131.5\left(\text { ocean water }^{3}\right) ; 38.5\left(\text { water }^{6}\right) ; 7110000\left({ }^{6}\right)\end{array}$ \\
\hline
\end{tabular}




\begin{tabular}{|c|c|c|c|c|c|}
\hline \multicolumn{5}{|c|}{ Values from this study } & \multirow{2}{*}{$\begin{array}{l}\text { Values reported elsewhere } \\
\text { (Data refer to sediments unless otherwise stated; number within brackets } \\
\text { indicates source in footnote) }\end{array}$} \\
\hline Element & Minimum & Mean & S.E. & Maximum & \\
\hline $\mathrm{Hg}$ & * & 6.41 & 1.47 & 83.30 & $66-180\left(^{4}\right) ; 1.8\left(\right.$ water, $\left.{ }^{6}\right) ; 6320\left({ }^{6}\right)$ \\
\hline $\mathrm{Mn}$ & 0.70 & 436.80 & 14.69 & 697.00 & $\begin{array}{l}\left.4980-438000\left({ }^{1}\right) ; 25\left(\text { spring and well water, }{ }^{2}\right) ; 1.8-40.8 \text { (ocean water, }{ }^{3}\right) \text {; } \\
\left.3738 \text { (coastal soils, }{ }^{5}\right) ; 7.4\left(\text { water, }^{6}\right) ; 412000\left({ }^{6}\right)\end{array}$ \\
\hline Mo & 0.20 & 1.62 & 0.46 & 26.15 & 24 (spring and well water, ${ }^{2}$ ) \\
\hline $\mathrm{Ni}$ & 7.58 & 76.08 & 18.84 & 1127.00 & $\begin{array}{l}\left.10800-37400\left(^{1}\right) ; 3\left(\text { spring and well water, }{ }^{2}\right) ; 0-12.1 \text { (ocean water, }{ }^{3}\right) ; 24.5 \\
\left(\text { coastal soils, }^{5}\right) ; 15900-44600\left(^{(}\right)\end{array}$ \\
\hline $\mathrm{Pb}$ & 0.32 & 19.30 & 0.98 & 34.19 & $\begin{array}{l}1.0-1.76\left(\text { soil }^{1}\right) ; 1460-10400\left({ }^{1}\right) ; 2\left(\text { spring and well water, }{ }^{2}\right) ; 3440-15590 \\
\left({ }^{4}\right) ; 74.0\left(\text { coastal soils, }^{5}\right) ; 2.3\left(\text { water, }^{6}\right) ; 12800\left({ }^{6}\right) ; 8046-15700\left(^{7}\right)\end{array}$ \\
\hline $\mathrm{Rb}$ & 0.18 & 36.37 & 1.65 & 76.94 & \\
\hline $\mathrm{Sb}$ & $*$ & 0.09 & 0.05 & 2.93 & $30-94\left({ }^{7}\right)$ \\
\hline $\mathrm{Sc}$ & $*$ & 6.05 & 0.37 & 8.98 & \\
\hline $\mathrm{Se}$ & $*$ & 0.17 & 0.05 & 1.43 & \\
\hline $\mathrm{Sn}$ & $*$ & 0.61 & 0.16 & 9.68 & $219-654\left({ }^{7}\right)$ \\
\hline $\mathrm{Sr}$ & 0.18 & 27.77 & 0.89 & 44.17 & 2200 (spring and well water, ${ }^{2}$ ) \\
\hline $\mathrm{Ti}$ & 4.61 & 475.39 & 26.26 & 1350.00 & $72-341()^{7}$ \\
\hline $\mathrm{V}$ & 0.09 & 32.93 & 1.14 & 51.65 & $13\left(\right.$ spring and well water, $\left.{ }^{2}\right) ; 18500-46900\left({ }^{7}\right)$ \\
\hline Y & 0.03 & 6.60 & 0.34 & 16.69 & \\
\hline $\mathrm{Zn}$ & 2.30 & 73.60 & 2.23 & 112.50 & $\begin{array}{l}\left.\left.35.0-56.2\left(\text { soil },{ }^{1}\right) ; 120-62200\left({ }^{1}\right) ; 2.4-20 \text { (ocean water, }{ }^{3}\right) ; 72.5 \text { (water, }{ }^{6}\right) ; \\
43200\left({ }^{6}\right) ; 24300-76000\left({ }^{7}\right)\end{array}$ \\
\hline
\end{tabular}

${ }^{1}$ Balasubramanian, 1999. ${ }^{2}$ Bond, R G \& Straub, C P (eds), $1973{ }^{3}$ Braganca\&Sanzgiri, 1980. ${ }^{4}$ IUCN Reports 1987. ${ }^{5}$ McGrath \& Loveland (1992). ${ }^{6}$ Sarkar, S.K. et al. 2003 ( Premonsoon data from the mouth of the Ganga estuary near Gangasagar used). ${ }^{7}$ Zöckler, C \& Bunting, G 2006.

The results of the analyses of the basic soil and water parameters such as percentage moisture content, $\mathrm{pH}$ and

EC are presented in differenttables.

Table 2.0. General Linear Model for the Soil Nutrient parameters in Sundarbans: Analysis of Variance results, testing for the two factors of Compartment and Plot, together with their interaction. Values given are the F-results together with probability levels. (Significant results are indicated with asterisks). (Key: $p>0.05$, N.S. ; $p<0.01, * * ; p<0.001, * * *)$.

\begin{tabular}{|c|c|c|c|}
\hline Soil NutrientsElement & CompartmentF $(2,46)$ & PlotF $(2,46)$ & InteractionF $(4,46)$ \\
\hline $\mathrm{Na}$ (Sodium) & $4.65, \mathrm{p}=0.014 * *$ & $2.14, p=0.13, \mathrm{NS}$ & $1.23, \mathrm{p}=0.31, \mathrm{NS}$ \\
\hline Exc. $\mathrm{Na}$ & $3.47, \mathrm{p}=0.039, * *$ & $0.22, p=0.80$, N.S & $1.08, p=0.38$, N.S \\
\hline Soluble-Na & $3.77, \mathrm{p}=0.031 * *$ & $2.20, p=0.12$, N.S. & $0.17, p=0.95, \mathrm{NS}$ \\
\hline Soil pH & $11.67, \mathrm{p}=0.000 * * *$ & $2.71, \mathrm{p}=0.07 * *$ & $7.46, \mathrm{p}=0.000 * * *$ \\
\hline S(Sulphur) & $4.51, \mathrm{p}=0.016^{* *}$ & $0.32, p=0.73$, N.S. & $1.86, p=0.13$, N.S \\
\hline CaCalcium & $0.37, p=0.69$, N.S & $2.17, \mathrm{p}=0.13$, N.S. & $1.60, \mathrm{p}=0.19, \mathrm{~N} . \mathrm{S}$. \\
\hline (Soluble) K(Potassium) & $1.67, p=0.20$, N.S. & $0.67, p=0.52$, N.S. & $1.64, \mathrm{p}=0.18, \mathrm{~N} . \mathrm{S}$. \\
\hline Exc. K(Exchangeable - Potassium) & $5.15, \mathrm{p}=0.01 * *$ & $1.15, p=0.33$, N.S. & $0.80, \mathrm{p}=0.53$, N.S. \\
\hline N (Total Nitrogen) & $0.63, p=0.54$, N.S. & $0.70, p=0.50$, N.S. & $1.02, p=0.40$, N.S. \\
\hline N (Soluble Nitrogen) & $0.32, p=0.73$, N.S. & $0.34, p=0.72$, N.S. & $0.80, p=0.53$, N.S. \\
\hline $\mathrm{Fe}$ (Iron) & $0.38, \mathrm{p}=0.69, \mathrm{NS}$ & $1.58, \mathrm{p}=0.22, \mathrm{NS}$ & $0.74, p=0.57, \mathrm{NS}$ \\
\hline
\end{tabular}

Table 3.0. Outcomes from the analyses using Spearman's Rank Correlation Coefficient of the relationship between severity of top-dying and various parameters of tree structure and growth (Key: NS=p>0.05; $=p<0.05)$.

\begin{tabular}{llll}
\hline Parameters comparing withTop-dying. & Correlation(r-value, with7df). & Probability(p-value) & Sig. orN.S \\
\hline Tree height $(\mathrm{m})$ & -0.113 & 0.773 & N.S \\
Tallest tree height $(\mathrm{m})$ & 0.072 & 0.854 & N.S \\
Bole diameter $(\mathrm{cm})$ & 0.067 & 0.865 & N.S \\
Tree density $\left(\mathrm{m}^{2}\right)$ & 0.021 & 0.956 & N.S \\
Soil Moisture Content Percentage (M.C. \%). & -0.736 & 0.024 & $*$ \\
\hline
\end{tabular}

\section{Discussion}

Although it is often difficult to pick out one predominant thread from the range of comments made by the respondents, it is clear that top-dying is a very prevalent problem which respondents were familiar with and believed to be getting worse; that this led to the view that the Sundarbans was not currently in a healthy state; and its regeneration of trees was getting worse (Awal, 2007). The fact that several different reasons were cited as possible causes of top-dying and the lack of a clear starting point for the problem, suggest that the true causes are likely to be varied and gradual in their effects, and quite possibly several factors interact to lead to the problem (Awal, 2007). In connection with the causes of top-dying indicated by these local people, and with the indications of health problems and their causes, it must be remembered that these are indications of what people think, but that these perceptions of causes might not be valid (Awal, 2007); external verification of the causes is required (Awal, 2007). It is notable; however, that local residents as well as 
forestry workers were keen to see better management of the Sundarbans (Awal, 2007), for their benefit as well as of the environment (Awal, 2007). It is likely that local residents who benefit from the Sundarbans will have recommended sustainable management approaches, but probably were not the people recommending an outright ban on all use of the forests, as a few respondents did. These results are indicated as follows: if one number (all values in ppb) is given it is a mean, otherwise if a range is given they are the minimum and maximum; the number is followed by the type of material from which the data come, with no text indicating it is from sediments (the most common material reported in the literature); finally, the number in brackets indicates the numbered reference source, the sources being indicated in the legend (Table 1.0). Besides attempting to establish whether the element concentrations are elevated or not, it is valuable to explore whether there is any marked spatial (as opposed to random) variation in the concentrations found (table 1.0), and also the nutrient concentrations included in Tables 2.0, while table 3.0 includes similar results for water parameters. Table 1.0 details the results for analysis of the heavy metals data from tables 1 and table 2.The results from the analyses of soil parameters (Table 1.0) show many of the parameters tested to be markedly different in the different compartments but, except for soil $\mathrm{pH}($ Awal, 2007), not to vary significantly either in the plot or in the interaction terms(Awal, 2007). Soil $\mathrm{pH}$ was, interestingly, highly or very highly significant with both factors and the interaction(Awal, 2007).It is not surprising that there are differences between the three compartments, as they had been selected in order to demonstrate a range of circumstances that might contribute to top-dying, such as nearness to human activity. As an example of the results shown in respect of this factor, The fact that there is no significant difference between plots for any parameters (other than $\mathrm{pH}$ ) may be an indication that there is little variation in these parameters over the relatively small distances between plots; or the selection of plots based on top-dying has not selected for variation in these parameters because they are not correlated with the amount of top-dying (Awal, 2007).

It is interesting that there were no significant interactions (apart from soil $\mathrm{pH}$ ). This indicates that the effects evident between compartments can be considered independently of any plot effecs-possibly operating at a broader geographical scale. Since soil $\mathrm{pH}$ showed significance in interaction as well as for the two factors separately, In general, it would appear that the higher the $\mathrm{pH}$ value, the higher the amount of top-dying(Awal, 2007).The pattern of variation between compartments is not consistent for the medium top-dying plots, but is consistent when comparing plots 1 and 3 in each compartment -compartment 31 having the highest $\mathrm{pH}($ Awal, 2007).

There were no significant variations in any of the parameters for the water samples (Awal, 2007), for compartments or for plots, although water $\mathrm{pH}$ was close to significance (Awal, 2007) when comparing between plots
(Table 2.0). This presumably implies that the water characteristics were quite consistent between different locations. This is, however, surprising given the significant differences in soil results in Table 1.0; for example, one might have expected water $\mathrm{Na}$ concentrations to vary in similar manner to soil $\mathrm{Na}$ values, since most of the soil $\mathrm{Na}$ has probably derived from that brought in by sea water. It is possible that soil $\mathrm{Na}$ reflects historical differences between compartments that are no longer evident in present daywater, i.e that water characteristics have changed notably in more recent periods (Awal, 2007).

The concentrations of the various heavy metals extracted from the soil samples, when analyzed by the two factors ANOVA with replication, gave rise to the results listed in Table 2.0. The majority of elements did not show any significant pattern to the results, for compartment, plot or interaction (Awal, 2007). However, seven elements, Bi, Exchangeable K, P, Sc, Sr and V, did show a significant difference between the three compartments(Awal, 2007), with compartment 26 having the greatest concentration of each of these elements and compartment 28 had the least (Awal, 2007). There were also a few other elements which showed results close to significance $(\mathrm{P}<0.10)$ which are also worth highlighting for further consideration(Awal, 2007), namely: Sb (plots were rather different); $\mathrm{Ca}$ (compartments showing variation); and In (both compartments and interactions were close to significance). With a large number of statistical tests, it is of course possible for occasional ones to be significant by chance; however, the proportion of tests which were significant or very close to it is higher than would be expected at random, and particularly with $\mathrm{Bi}$ and $\mathrm{V}$ the significance level was high (Awal, 2007), and therefore it can be started confidently that there are substantive variations in at least some of these chemical elements between different compartments and (with less confidence) some variations between plots(Awal, 2007).

It is desirable to assess whether the chemical characteristics of soil or water have affected the growth of trees(Awal, 2007). Table 3.0 includes the results of Pearson's correlation analyses where the various parameters are being assessed for relationship with tree height data (Awal, 2007). Although correlation is not a method of analysis that presumes causality, it might nevertheless be justified in interpreting any significant correlation as evidence that the relevant chemical feature was causing an increase or decrease in tree height at higher values (Awal, 2007).However, none of the parameters tested showed a significant relationship with tree height, with exchangeable $\mathrm{Na}$ being the only element that even came close $(p<0.10)$ (Awal, 2007). Therefore, it does not appear that tree height is substantially affected by the parameters tested (Awal, 2007). It should be remembered that illicit felling of trees does occur in the areas studied (Awal, 2007), and it is possible that this extra factor might be influencing these results by selectively removing the largest trees, and making it more difficult for any 
correlation to be established (Awal, 2007).

Similar results may be demonstrated when comparing the same parameters with tree diameter (Table 3.0). In this case, however, not only exchangeable $\mathrm{Na}$ but also $\mathrm{Pb}$ gave results close to significance, while exchangeable $\mathrm{K}$ did reach the threshold of significance at the 5\% level (Awal, 2007). The negative correlation for $\mathrm{K}$ shows that an increase in the amount of $\mathrm{K}$ is associated with a decrease in the girth of the trees. This is an unexpected result, as it might be expected that providing extra nutrients to the trees should lead to them growing better. It is unclear what might be leading to the relationship actually observed (Awal, 2007). A primary objective of the present work is to establish whether the concentrations of the various chemical elements, or other soil or water parameters, are having an influence on the amount of top-dying believed to exist in the different plots. To this end, correlations have been determined between the topdying index and the various parameters (Awal, 2007). The various heavy metal concentrations, arising from the ICP-MS work, were tested using Spearman's rank correlation coefficient, with the results included in Table3.0. There were no elements which gave a significant correlation with the index of top-dying, although $\mathrm{Sn}$ gave a (negative) correlation which was close to significant $(\mathrm{p}<0.1)$. It is clear that, within the scope of the present samples and data collected, there is no indication that heavy metal concentrations are influencing the amount of top-dying, with the possible exception of $\mathrm{Sn}$ (Awal, 2007).

Therefore, it was decided to test the Sn data, as well as data for a few other heavy metals (those with the strongest correlations in the previous tests), using the Pearson's correlation coefficient instead in order to assess how different the results would be if the data were treated as fully quantitative (Awal, 2007). The result for Sn has changed probability slightly, but sufficiently to become significant, while the result for $\mathrm{Pb}$ has moved to becoming less than $10 \%$ significance (Awal, 2007). All other results were clearly non-significant (Awal, 2007). Consequently it may be concluded that there is very little in terms of chemical parameters that shows any clear relationship with the amount of top-dying, with $\mathrm{Sn}$ and possibly $\mathrm{Pb}$ being the only elements with any notable effect (Awal, 2007). It may also be concluded that, while use of the quantitative Pearson's correlation coefficient slightly increases the significance of the results, it does not substantially change the conclusions that arose from using the rank correlation technique (Awal, 2007).

\section{Conclusions}

The heavy metal concentrations and other soil and water parameters tested in general did not show significant correlations with either the growth parameters for the trees or for the amount of top-dying as determined by the index of severity, although there were a few exceptions (Awal, 2007). However, there were significant differences between the compartments in a number of the parameters tested
(Awal, 2007). The overall conclusions from the results presented in this section are that the selection of sites has not produced clear statistical differences in the amount of top-dying evident; probably because of the way the data were collected (Awal, 2007). However, it is believed that there is notable variation between plots and compartments (Awal, 2007), and certainly this seems to be reflected in the ability of the trees to regenerate (Awal, 2007). However, the link between top-dying and the size of the trees is not clear, with tree height and diameter not being directly related consistently to amount of top-dying, although moisture content of soil was inversely related (Awal, 2007). Since the great majority of trees present in all plots is the species Heritierafomes, this means that the comments above are essentially referring to the response of this species rather than that of any others (Awal, 2007).

\section{References}

[1] Awal, M.A. (2007). Analysis of possible environmental factors causing top-dying in mangrove forest trees in the Sundarbans in Bangladesh. PhD thesis, University of Bradford.

[2] Awal, M.A., Hale, W.H.G. \& Stern, B. (2009). Trace element concentrations in mangrove sediments in the Sundarbans, Bangladesh. Marine Pollution Bulletin, 58(12), 1944-1948.

[3] Awal, M.A. (2014). "Correlation between the chemical composition of the surface sediment and water in the mangrove forest of the Sundarbans, Bangladesh, and the regeneration, growth and dieback of the forest trees and people health".Journal of Science Innovation; 2014. 2(2): pp.11-21.Science Publishing Group, USA; May 20th, 2014(2):11-21; doi: 10.11648/j/si.20140202.11.

[4] Anonymous, 1975. Under-exploited tropical plants with promising economic value. National Academy of Sciences, Washington.

[5] Bangladesh Bureau of Statistics, 2006. Statistical Yearbook of Bangladesh, Statistics Division. Ministry of Planning. Dhaka, Bangladesh.

[6] Bari, A. 1993. Afforestation and the nutrient sink. Assistance to Fisheries Research Institute. Mymensingh. BGD / 89 / 012, Field Document-3.

[7] BFRI, 1990-95. Annual Research Report. Silviculture Genetics Division. Bangladesh Forest Research Institute (BFRI), Chittagong, Bangladesh.

[8] Briggs, J.C. (1991). Global species diversity. Journal of Natural History, 25:1403-1406.

[9] Burns, K.A; S. D. Garrity, and S.C. Levings. 1993. How many years until mangrove ecosystems recover from catastrophic spills? Marine Pollution Bulletin26 (5): 239248 .

[10] Chaffey, D. R; Miller, F.R; Sandom, J. H. 1985. A forest inventory of the Sundarbans, Bangladesh, Main report, Project Report No.140, 196 pp; Overseas Development Administration, London, U.K:195-196. 
[11] Chantarasri, S. 1994. Integrated Resource Development of the Sundarban, Fisheries Resources Mangagement for the Sundarban, UNDP / FAO, BGD / 84 / 056, Khulna, Bangladeshp: 170-172.

[12] Currie, J. A. 1984. Gas diffusion through soil crumbs: the effects of compaction and wetting. Journal of Soil Science. 35: $1-10$.

[13] FAO / UNEP, 1981. Food loss Prevention in Perishable Crops. FAO Agricultural Services Bull, 43, Italy, Rome.

[14] FAO, 1982. Management and utilization of mangroves in Asia and the Pacific.1982. FAO Environment Paper, 3.Rome:160-168.

[15] FAO, 1994. Review of the state of world marine fisheries resources. FAO Fisheries resources. FAO Fisheries Technical Approach Paper 335:143.

[16] FAO, 1997. State of the World's Forests. Food and Agriculture Organization of the United Nations. Rome, Italy.

[17] Government of Republic of Bangladesh, 1985. The draft of (1985-90) 5th five year plan, Dhaka, Bangladesh.

[18] Government of Bangladesh, (1993). Forestry Master Plan: Executive Summary. Asian Development Bank, UNDP/FAOBGD/88/025, Forest Department, Government of Bangladesh, Dhaka.31p.

[19] Guha, R. (1989). Radical American Environmentalism and Wilderness Preservation: A Third World Critique. Environmental Ethics, 11, pp.71-83.

[20] Hambrey, J. 1999. Mangrove, Fisheries and Economic. Aquaculture and Aquatic Resource Management Program. Asian Institute of Technology. Thailand: 1-4.

[21] Hussain, Z. and Karim, A. (1994). Introduction. In: Mangroves of the Sundarbans. Volume 2: Bangladesh, Z.
Hussain and G. Acharya (Eds.) IUCN. Bankok, Thailand. !$18 \mathrm{pp}$.

[22] Islam, A. K. M. N. 1973. The algal flora of the Sundarbans mangrove forest of Bangladesh. Bangladesh Journal of Botany. 2 (2): 11-36.

[23] Khan, J. A. 1997. Estimation of unregulated densities by line transects method in Gir forest, India. Tropical Ecology. 38(1): $65-72$.

[24] Mukharjee, A. K. 1975. The Sundarbans of India and its biota. Journal of Bombay Natural History Society, 72 (1):120.

[25] Phillips, O. L; Hall, P; Gentry, A.H.; Sawyer, S. A; and Vasques, R. 1994. Dynamics and species richness of tropical forests. Proc. Natural Acad. Society. U.S.A.91: 2805-2809.

[26] Seidensticker, J. Hai; A. 1983. The Sundarbans wildlife management plan: conservation in the Bangladesh (cited in Chaffey et al., 1985), Bangladesh.

[27] Seidensticker, J. \& Hai, M.A. 1983. The Sundarbans Wildlife Management. Bangladesh coastal zone. International Union for Conservation of Nature. Gland, Switzerland.

[28] Singh, K.P \& Singh, J.S. 1988. Certain structural functional aspects of dry tropical forest and savanna. International Journal of Ecology and Environmental Sciences 14:31-45.

[29] Sokal, R.R. and Rohlf, F.J. (1981). Biometry. San Francisco, w.H. Freeman.

[30] Status Report, Government of India, 1987; and India Remote Sensing Data (Nayak, 1993). Mangroves in India. India.

[31] UNESCO, 1997. Convention Concerning the Protection of the World Cultural and Natural Heritage, France, Paris. 